\title{
Comparing audio- and video-delivered instructions in dispatcher-assisted cardiopulmonary resuscitation with drone-delivered automatic external defibrillator: A mixed methods simulation study
}

\author{
Hyun-Jung Kim ${ }^{1}$, Jin-Hwa Kim ${ }^{2}$, Dahye Park ${ }^{\text {Corresp. } 3}$ \\ ${ }^{1}$ Department of Nursing, Daewon University College, Jecheon, Chungbuk, Republic of Korea \\ 2 Department of Emergency Medical Technology, Daewon University College, Jecheon, Chungbuk, Republic of Korea \\ 3 Department of Nursing, Semyung University, Jecheon, Chungbuk, South Korea \\ Corresponding Author: Dahye Park \\ Email address: dhpark@semyung.ac.kr
}

This study compared first responders' cardiopulmonary resuscitation (CPR) performance when a dispatcher provides audio instructions only and when both audio and video instructions are given. In the simulation, an automatic external defibrillator (AED) was delivered via drone in response to a cardiac arrest occurring outside a hospital setting. Participants' qualitative experiences were also explored. An exploratory sequential mixed methods design was used. AEDs were delivered to college students via drone with one group receiving both audio and video instructions and the other receiving audio-only instruction, and differences in CPR performance and accuracy were compared. After completion, focus group interview data were collected and analyzed. Video-based instruction was found to be more effective in the number of chest compressions ( $p<$ $0.01)$, chest compression rate $(p<0.01)$, and chest compression interruptions $(p<0.01)$. The accuracy of the video group for the chest compression region was high $(p=0.05)$. Participants' experiences were divided into three categories: "unfamiliar but beneficial experience," "met helper during a desperate and embarrassing situation," and "diverse views on drone use." Our results lay the groundwork for a development plan for providing emergency medical services using drones, as well as the preparation of guidelines for dispatchers on the provision of video instructions. 


\section{Comparing audio- and video-delivered instructions in 1 dispatcher-assisted cardiopulmonary resuscitation 2 with drone-delivered automatic external defibrillator: A 3 mixed methods simulation study

Hyun-Jung Kim¹, Jin-Hwa Kim², Dahye Park ${ }^{3}$,

${ }^{1}$ Department of Nursing, Daewon University College, Republic of Korea 6

2 Department of Emergency Medical Technology, Daewon University College, Republic of $\quad 7$ Korea

${ }^{3}$ Department of Nursing, Semyung University, Republic of Korea

Corresponding Author:

Dahye Park ${ }^{3}$

Department of Nursing, Semyung University,

\section{Abstract}

This study compared first responders' cardiopulmonary resuscitation (CPR) performance when a 18 dispatcher provides audio instructions only and when both audio and video instructions are

response to a cardiac arrest occurring outside a hospital setting. Participants' qualitative

experiences were also explored. An exploratory sequential mixed methods design was used.

AEDs were delivered to college students via drone with one group receiving both audio and

video instructions and the other receiving audio-only instruction, and differences in CPR

performance and accuracy were compared. After completion, focus group interview data were

collected and analyzed. Video-based instruction was found to be more effective in the number of 
Despite advances in medical technology and improvements in economic standards, the prevalence of heart disease and resulting mortality rates are rapidly increasing in Korea due to the aging social structure and westernized eating habits. Rapid and appropriate cardiopulmonary experiencing cardiac arrest (Lu, Fang \& Lin, 2019). Brain damage occurs 4 min after the onset of 39 cardiac arrest, and after $10 \mathrm{~min}$, the person will suffer irreversible brain damage or brain death. Therefore, immediate administration of first aid is critical in determining whether the patient is resuscitated (Perkins et al., 2015). In addition, the mortality rate increases by $7-10 \%$ every minute a patient experiences cardiac arrest rhythms that require defibrillation. Therefore, shortening the time from cardiac arrest to defibrillation is an important factor in patient survival (Hallstrom, Ornato \& Weisfeldt, 2004).

The average arrival time of ambulances in Korea is 9 min (Jang et al., 2016). To improve patient survival rates and neurological prognosis in cardiac arrest, there is a need for medical services that can rapidly deliver automatic external defibrillator (AED) devices.

A geographic information system model that can be used to deliver drones to patients of our knowledge, no studies have yet used drone-delivered AEDs in actual situations in Korea. quickly deliver defibrillators to the site of cardiac arrest.

It is not only important to provide medical services promptly in the event of cardiac arrest, but also to provide the services accurately. Accordingly, to increase the rate of CPR during cardiac arrest, it was performed based on the dispatcher's instructions. In the event of an out-ofhospital cardiac arrest, dispatchers provide guidance to callers, helping them confirm cardiac arrest and initiate CPR until emergency rescuers arrive (Lee et al., 2020). Currently, dispatchers provide verbal CPR guidance to bystanders via mobile phone. However, it is difficult to confirm whether the CPR performer correctly understands and follows the audio instructions of the dispatcher (Williams, et al., 2006). To address this problem, a mobile phone with a two-way video call function can be used to provide both audio and video instructions, allowing immediately (Lin et al., 2017). However, this multimedia approach has not been generalized, and 
site of a cardiac arrest outside a hospital, and explored the experience provided by the audio- and 73

video- instruction CPR using drones and how it affected the CPR process.

Materials \& Methods

Design

This study followed an exploratory sequential mixed method design. For the quantitative component, AEDs were delivered to college students by drones and CPR instructions were delivered by a dispatcher. A nonequivalent control group posttest only design was conducted between the group that received audio-only instructions and the group that received mixed video and audio instructions, to compare differences in CPR performance and accuracy. For qualitative research, after the participants' experiments were completed, data were collected and analyzed through focus group interviews. The study was conducted according to the guidelines of the Declaration of Helsinki, and approved by the Ethics Committee of the University of Semyung (protocol code SMU-2020-07-003 and date of approval August 7, 2020). Written informed consent has been obtained from all participants for their data to be used for scientific research. Instruments

The drone used to transport the AED was equipped with a satellite positioning system (GPS) and high-definition camera (Figure 1; maximum load: $16 \mathrm{~kg}$, maximum cruising speed: $10 \mathrm{~m} / \mathrm{s}$, maximum altitude: $2000 \mathrm{~m}$, JW002).

The CPR performance evaluation was performed using Resusci Anne ${ }^{\circledR}, \mathrm{QCPR} \circledast$ manikin (Laerdal, Norway) and a CPR quality assessment program connected to the manikin (Laptop PC, 95 Laerdal, Norway with Sim Pad Skill Reporter and Resusci Anne ${ }^{\circledR}$ Wireless Skill Reporter 96 software installed; Figure 2). The scores were automatically recorded and saved by the Sim Pad Skill Reporter. Three evaluators were present to assess the accuracy of participants' movements 98 and sequences that could not be evaluated by the Sim Pad Skill Reporter. Performance was 99 judged based on the following criteria: consciousness confirmation ( 2 points), help request (2 100 points), breathing confirmation (4 points), airway management (4 points), artificial respiration 101 (24 points: 8 points $\times 3$ cycles), chest compression ( 24 points: 8 points $\times 3$ cycles), and 102 automatic defibrillator use (10 points). Users were given 0 points for a poor performance, 1 point 103 for average, and 2 points for good. The total score of the three evaluators was calculated as the 104 average score, and the time taken from the arrival of the AED to the execution of the 105 defibrillation was measured using a stopwatch. The AED was a fully automatic Laerdal® AED 106 Trainer 2 (Medtronics, Physiocontrol, USA), as shown in Figure 3.

[Figure 2 here] 109

[Figure 3 here] 110 
The focus group instrument consisted of three main types of questions. The first,

"What was the experience like for dispatchers giving audio and video CPR instructions?")

Closing questions provided space for additional statements and thoughts related to the drones

The experiment was conducted in a location with adequate lighting and where external noise was blocked. Consenting participants, who were eligible to participate in the study, were randomly allocated to either the group receiving audio-only instructions or the group receiving mixed video-audio instructions. Group randomization was based on a computer-generated sequence list. The randomized list was prepared by an independent research assistant who was not involved in recruiting participants and concealed in sequentially numbered, sealed, opaque envelopes. Participants acted alone as the first bystander and rescuer in a simulated situation where cardiac arrest was suspected. Participants were notified on the day of the experiment that an automatic defibrillator would be delivered using a drone. The participants performed CPR by

Three CPR motion evaluators and one dispatcher were standardized through pre-evaluation and training, each with over 10 years' experience as a first-class emergency medical technician or BLS-P-Instructor for the American Heart Association. The motion evaluators rated the performance of the control and experimental groups. The evaluators could not hear the dispatcher's instructions, which allowed them to judge the CPR performances based on motions only.

The guidance programed on the virtual 119 phone call explained the CPR algorithm (video/audio guidance) and informed the callers that ambulances and drones were being deployed. Based on a previous study (Claesson et al., 2017), the simulated flight time of the drone was set to $5 \mathrm{~min}$. After CPR had been performed for $5 \mathrm{~min}$, it was announced that an automatic defibrillator was delivered to the ground using a drone at a point $50 \mathrm{~m}$ from the to the manikin.

Audio instruction (control group) method and video instruction (experimental group) method

The dispatcher conducted the training in an office isolated from the participants. The audio 
participant's understanding and performance using a basic mobile phone. The dispatcher wore a 152 Bluetooth headset (SHM-612) capable of verbally transmitting and receiving CPR instructions. 153 Video instructions (experimental group) were performed using a video mobile phone. The phone 154 had a 12-megapixel camera with a resolution of $2220 \times 1080$ capable of two-way video calls, 155 and a Galaxy S8+, SM-G955U1 model with an HSDPA 150 Mbps (upload transmission rate). 156 The dispatcher, while assessing the participant's CPR performance through the audio and video, 157 provided instructions, according to the American Heart Association guidelines, on things such as 158 CPR sequence and posture correction.

Data collection

In Sanfridsson et al.'s (2019) mixed study, 16 people were tested and interviewed.

Moreover, for content analysis, a qualitative research method, interview data from five to 25

people is considered appropriate (Cresswell \& Plano Clark, 2007). In this study, there were 24

To minimize the difference between the experiments in terms of collecting quantitative data,

To collect qualitative data, focus group interviews were conducted with the 24 participants. Semi-structured interviews were conducted in groups of four to six participants, using openended questions. The participants agreed to participate in the recorded interviews, which were conducted in a quiet and comfortable seminar room.

\section{Quantitative data analysis}

The data were analyzed using SPSS Windows 25.0. First, participants' general rank test, a nonparametric statistical method.

\section{Qualitative data analysis}

In the post-experiment interview, open questions were used; participants' responses were 
described as universal and abstract concepts. Finally, the organized categories were 192 comprehensively described so that the phenomena experienced were well revealed from the 193 participants' point of view. The researchers reviewed previous studies on related content and 194 continuously checked to ensure that their subjectivity did not intervene in the analysis process. 195 For the analyzed data, the peer examination was conducted by one professor in the department of 196 nursing with extensive experience in qualitative research and one researcher who completed a 197 qualitative research methodology class in graduate school.

\section{Results}

\section{General characteristics of participants}

Twelve participants received verbal CPR instructions, and 12 received CPR instructions over video. There was no significant difference in gender, age, height, and weight between the two groups, and thus, homogeneity was ensured (Table 1).

\section{CPR performance}

The number of chest compressions was $96.92 \pm 12.33$ in the audio instruction CPR group, and $121.42 \pm 17.23$ in the video instruction CPR group $(\mathrm{p}<0.01)$. The rate of chest compression was group $(\mathrm{p}<0.01)$. The hands-off time during chest compressions was $17.08 \pm 2.71 \mathrm{~s}$ in the audio instruction CPR group, and 10.83 $\pm 2.92 \mathrm{~s}$ in the video instruction CPR group $(\mathrm{p}<0.001)$. There compressions, and stopping time.

In artificial respiration, the total respiration rate was $3.50 \pm 2.20$ times in the audio instruction CPR group and 5.50 \pm 2.75 times in the video instruction CPR group, showing a significant

\section{CPR accuracy}

The Cronbach's alpha of the total CPR accuracy score by the three evaluators was 0.91 . The 
instruction CPR group $(\mathrm{p}=0.05)$. The score for 1 st cycle chest compression was $7.69 \pm 0.45$ in 232 the audio instruction CPR group and 8.00 \pm 0.00 in the video instruction CPR group, respectively 233 $(p=0.01)$. The results showed that the accuracy of CPR, as gauged by the evaluators, was 234 significantly higher in the video instruction CPR group in terms of consciousness check, $119 \quad 235$ report and defibrillator request, and chest compressions compared to the audio instruction CPR 236 group (Table 3). 237

[Table 3 here] 239

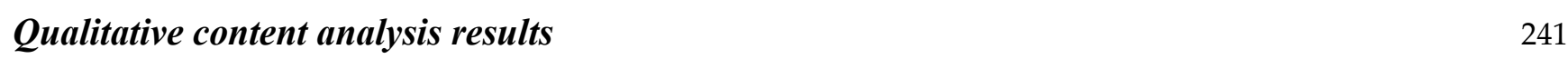

From the content analysis of the participants' post-experiment responses, six subcategories were extracted, from which three main categories were derived (Table 4).

This category includes the subcategories of "regret for poor performance" and "vibrancy, as

Regret for poor performance. Participants commented on experiences in which smooth

On the other hand, some students who had already completed BLS-P training were

Some participants were also hindered by uncontrolled situational variables. For example, the defibrillator sounds made it difficult to hear the call. 
"In the case of audio instruction, there is a risk that the mobile phone connection may not be successful, or the connection may be disconnected due to battery discharge." (Participant 19)

Vibrancy, as if experiencing a real situation. Most participants initially had doubts about in the simulated situation as if they had actually experienced it, and that this experience would help a lot in actual practice in the future.

"I think I had a good experience by performing the simulation well as in the real world. I think this simulation is a good idea." (Participant 1)

This category includes the subcategories of "comfort that you are not alone" and "compensation for insufficiencies." Most participants relied on the dispatcher and the drone to compensate for their lack of knowledge and insufficient skills; thus, they resolved the situation.

Comfort that you are not alone. Most of the participants said they felt anxious, scared, and that the drone provided them emotional comfort.

Compensation for insufficiencies. In situations where the participants had to perform CPR

This category includes the subcategories of "contradictory feelings about drone size" and

Conflicting feelings about drone size. Most participants thought the drone was too big, making it dangerous for both the patient and rescuer during takeoff and landing.

"This is my first experience, but there seems to be a danger to both the requestor and the rescuer

However, one participant was satisfied with the large size of the drone, saying that it looked

"It was amazing and impressive that the drone looked so big and sturdy that it could deliver an AED through it." (Participant 14)

Varying views on the accessibility of drones. Most participants thought the method of (2) 
defibrillators, such as in the mountains or in remote areas, and they expected that the quality of

311

CPR would be improved compared to conventional single-person CPR.

312

"I felt it was really practical. If I met a patient with cardiac arrest while hiking, I never thought of what a drone would bring in an environment without an AED." (Participant 22)

However, the participants highlighted some points for improvement. Some judged it not to be effective in this case because large drones could not access narrow places with lots of grass or leaves. In addition, many participants found that it was difficult to use the drone on uneven terrain because it is difficult for the drone to land on a slope. As the drone is so large, the AED landing location may be some distance away from the patient, considering the length of the wings.

"When the AED arrived, it was so far away from the patient that it was unfortunate that there was a gap in the middle. I thought it would be better if the AED could come slightly closer to the patient." (Participant 1)

\section{Discussion}

This study compared the difference in CPR performance and the accuracy of the first responder based on whether audio or video instructions were given by a dispatcher during a cardiac arrest outside a hospital setting. We also attempted to provide basic data that can be used to increase the effectiveness of out-of-hospital CPR by confirming the experience of audio and video CPR instruction and exploring how CPR performance is affected when a defibrillator is delivered using a drone.

To increase the survival rate of patients with cardiac arrest, it is important for first responders to use high-quality CPR and rapid defibrillation. For high-quality CPR, chest compressions should be performed at a rate of 100 to 120 times $/ \mathrm{min}$, chest compressions at a depth of $5 \mathrm{~cm}$ or more, and the interruption time of chest compressions should be minimized (within $10 \mathrm{~s}$ ) (Perkins et al., 2015). First, regarding difference in CPR performance based on instruction delivery method in this study, the number and rate of chest compressions were higher in the video instruction group than in the audio instruction group, and the interruption time was shorter in the video instruction group than the audio instruction group. Though these results are consistent with that of Lin et al.'s (2017) study, thereby, confirming that the quality of CPR provided by the first responders based on audio and video instructions, the chest compression rate was higher in the video instruction group. Additionally, Ho et al.'s (2016) study found that when CPR was performed by a first responder based on the dispatcher's audio instructions the CPR initiation rate was lower and CPR delayed, which is similar to Dong et al.'s (2020) study which found that a smartphone application providing real-time monitoring and audiovisual feedback consistently maintained a higher rate compared to voice-directed CPR. Although these studies proved that video instruction is more useful in cardiac arrest situations, in Korea, audio instructions from the dispatcher are more widely used to help first responders in cardiac arrest situations outside a hospital. It is necessary to expand CPR guidance through video instructions from dispatchers to improve the quality of CPR in Korea, where the IT industry is developing, and mobile phones are widely used. A study on first responders' experiences with the delivery of
313 
AEDs via drones to the elderly showed some difficulties in using cell phones (Sanfridsson et al., 2019), attaching electrodes, and placing electrodes. Since the age range of first responders may vary, the image instruction method should therefore be included in the educational content of the difference was not statistically significant. Similar results were found in a study comparing video-based CPR education with traditional CPR education (Chien et al., 2020). Therefore, when the dispatcher provides CPR instruction, guidelines should be prepared to emphasize sufficient be further activated.

In terms of CPR accuracy, judged by three evaluators, the chest compression score, which instruction group. Lin et al. (2017) found audio instructions are limited in that it is not possible to confirm the actions of the first responder; however, with video instruction, problems can be corrected through feedback by confirming the actions of the first responder by audio and video.

The accuracy of chest compression by the audio instruction group was high in 1st cycle of chest compressions, but there was no difference from the audio instruction group in the 2nd and 3rd cycles. It is necessary to confirm whether there is no difference between the two groups because of the rescuer becoming fatigued over time. In addition, considering that the average arrival time can be maintained continuously while checking the performance of the rescuer, and a dispatcher video instruction guide should be developed accordingly.

In-depth understanding of the experience of drone use, audio instruction CPR, and videoinstruction was further analyzed, and the effect of experience on the CPR process was analyzed. When the drone delivered the automatic defibrillator, three categories of experience were derived: "an unfamiliar but beneficial experience," "met helper during a desperate and embarrassing situation," and "diverse views on drone use." The category of "unfamiliar but beneficial experience" included the subcategories of "regret about poor performance" and vibrancy, as if experiencing a real situation." The experience was unfamiliar because the provision of medical services via drone is not a common practice, and it was judged by the them. In addition, some of the study participants who had obtained the BLS-P qualification were concerned about the delay in intervention in coping with the CPR instructions as they were 
than in a real-life situation. Therefore, for the dispatcher and first responder to effectively

interact in a cardiac arrest situation, video instruction that can confirm the appropriateness of the experience, minimal intervention is better.

The category of "met helper during a desperate and embarrassing situation" included the subcategories of "comfort that you are not alone" and "compensation for insufficient areas." In a study by Sanfridsson et al. (2019), the interaction with the dispatcher offered participants a sense of relief and dependence, and they could handle emergency situations and perform given tasks properly perform CPR provided comfort to the rescuer that they were not alone, and the dispatcher could compensate for the rescuer's shortcomings.

The category of "diverse views on the use of drone" included the subcategories of "contradicting feelings about drone size" and "varying views on drone accessibility." Most participants thought the drone was too big, making it dangerous during takeoff and landing. However, the results of a previous study found AED delivery by drones to be safe and not difficult (Sanfridsson et al., 2019). To reduce the safety concerns and anxiety of rescuers, a safe distance should be secured, and the dispatcher's comments should be included in the audio and video instructions. Most participants said it would be useful to receive a defibrillator via drone in an environment where AEDs are not readily available. They were also positive about the accessibility of the drones, saying that receiving a defibrillator quickly can improve the quality of CPR compared to conventional CPR by a single rescuer. Some participants felt that to be

This study has several strengths. First, it demonstrated that delivering defibrillators using

\section{Conclusion}

This study provided evidence that there are differences. in performance, execution time, and accuracy of CPR performed by first responders, according to whether the dispatcher provides 
audio or video instructions, when an automatic defibrillator is delivered via drone during a

To activate medical services using drones, based on the current results, we propose a comparative study on the delivery of defibrillators using drones, and the transportation of defibrillators using ambulances after analyzing the routes appropriate for the region and terrain. Generalizability of the findings are severely limited because there is no system that uses AEDdrones, currently. In addition, we propose that a follow-up study confirm the efficacy by developing a dispatcher guide that uses audio and video instructions. Additionally, further studies are required to confirm the effects of audio and video instructions on various age groups and in different areas and terrains where there are no restrictions on drones' takeoff and landing.

\section{References}

Boutilier, J.J.; Brooks, S.C.; Janmohamed, A.; Byers, A.; Buick, J.E.; Zhan, C.; Schoellig, A.P.;

Chien, C.Y.; Fang, S.Y.; Tsai, L.H.; Tsai, S.L.; Chen, C.B.; Seak, C.J.; Weng, Y.M.; Lin, C.C.; Chien, W.C.; Huang, C.H.; Lin, C.Y.; Chaou, C.H.; Liu, P.H.; Tseng, H.J.; Chen, J.C.; Peng, S.Y.; Cheng, T.H.; Hsu, K.H.; Ng, C.J. Traditional versus blended CPR training program: a randomized controlled non-inferiority study. Sci Rep 2020, 10:10032. doi:10.1038/s41598-020-67193-1.

Claesson, A.; Bäckman, A.; Ringh, M.; Svensson, L.; Nordberg, P.; Djärv, T.; Hollenberg, J. Time to delivery of an automated external defibrillator using a drone for simulated out-ofhospital cardiac arrests vs emergency medical services. JAMA 2017, 317(22), 2332-2334. doi:10.1001/jama.2017.3957.

Claesson, A.; Fredman, D.; Svensson, L.; Ringh, M.; Hollenberg, J.; Nordberg, P.; Rosenqvist, M.; Djarv, T.; Österberg, S.; Lennartsson, J.; Ban, Y. Unmanned aerial vehicles (drones) in out-of-hospital-cardiac-arrest. Scand J Trauma Resusc Emerg Med 2016, 24(1), 124. doi:10.1186/s13049-016-0313-5. 
Dong, X.; Zhang, L.; Myklebust, H.; Birkenes, T.S.; Zheng, Z.J. Effect of a real-time feedback smartphone application (TCPRLink) on the quality of telephone-assisted CPR performed by trained laypeople in China: a manikin-based randomized controlled study. BMJ Open 2020, 5(10):e038813, 1-10. doi:10.1136/bmjopen-2020-038813.

Elo, S.; Kyngäs, H. The qualitative content analysis process. J Adv Nurs 2007, 62(1), 107-115. doi:10.1111/j.1365-2648.2007.04569.x.

Hallstrom, A.P.; Ornato, J.P.; Weisfeldt, M. The public access defibrillation trial Investigators. Public-access defibrillation and survival after out-of hospital cardiac arrest. $N$ Engl J Med 2004, 351, 637-646. doi:10.1056/NEJMoa040566.

Ho, A.F.W.; Sim, Z.J.; Shahidah, N.; Hao, Y.; Ng, Y.Y.; Leong, B.S.H.; Zarinah, S.; Teo, W.K.L.; Goh, G.S.Y.; Jaafar, H.; Ong, M.E.H. Barriers to dispatcher-assisted cardiopulmonary resuscitation in Singapore. Resuscitation 2016, 105, 149-155. doi:10.1016/j.resuscitation.2016.05.006.

Ho, A. F. W.; Liu, Z.; Wah, W.; Fook-Chong, S.; Pek, P. P.; Lo, H. Y.; Teo, R. M.; Poon, B. H.;

$\mathrm{Ng}, \mathrm{Y}$. Y.; Ong, M. E. H. Evaluation of culture-specific popular music as a mental metronome for cardiopulmonary resuscitation: a randomised crossover trial. Proceedings of Singapore Healthcare 2019, 28(3), 159-166. doi:10.1177/2010105818820544.

Jang, K.H.; Kang, K.H.; Jang, Y.H.; Hahn, K.D. Analysis of the time intervals in 119 ambulance services. Fire Sci Eng 2016, 30(4), 128-134. doi:10.7731/KIFSE.2016.30.4.128.

Lee, S.Y.; Song, K.J.; Shin, S.D.; Hong, K.J.; Kim, T.H. Comparison of the effects of audioinstructed and video-instructed dispatcher-assisted cardiopulmonary resuscitation on resuscitation outcomes after out-of-hospital cardiac arrest. Resuscitation 2020, 147, 12-20. doi:10.1016/j.resuscitation.2019.12.004

Lin, Y.Y.; Chiang, W.C.; Hsieh, M.J.; Sun, J.T.; Chang, Y.C.; Ma, M.H.M. Quality of audioassisted versus video-assisted dispatcher-instructed bystander cardiopulmonary resuscitation: a systematic review and meta-analysis. Resuscitation 2017, 123, 77-85. doi:10.1016/j.resuscitation.2017.12.010.

Lu, C.H.; Fang, P.H.; Lin, C.H. Dispatcher-assisted cardiopulmonary resuscitation for traumatic patients with out-of-hospital cardiac arrest. Scand J Trauma Resus Emerg Med 2019, 27(1), 97. doi:10.1186/s13049-019-0679-2.

Perkins, G.D.; Jacobs, I.G.; Nadkarni, V.M.; Nadkarni, V.M.; Berg, R.A.; Bhanji, F.; Biarent, D.; 504 Bossaert, L.L.; Nadkarni, V.M.; Berg, R.A.; Bhanji, F.; Biarent, D.; Bossaert, L.L.; Brett, S.J.; Chamberlain, D.; de Caen, A.R.; Deakin, C.D.; Finn, J.C.; Gräsner, J.T.; Hazinski, M.F.; Iwami, T.; Koster, R.W.; Lim, S.H.; Ma, M.H.M.; McNally, B.F.; Morley, P.T.; Morrison, L.J.; Monsieurs, K.G.; Mont-gomery, W.; Nichol, G.; Okada, K.; Ong, M.E.H.; Travers, A.H.; Nolan, J.P.; Aikin, R.P.; Böt-tiger, B.W.; Callaway, C.W.; Castren, M.K.; Eisenberg, M.S.; Kleinman, M.E.; Kloeck, D.A.; Kloeck, W.G.; Mancini, M.E.; Neumar, R.W.; Ornato, J.P.; Paiva, E.F.; Peberdy, M.A.; Soar, J.; Rea, T.; Sierra, A.F.; Stanton, D.; Zideman, D.A. Cardiac arrest and cardiopulmonary resuscitation outcome reports: update 
of the Utstein resuscitation registry templates for out-of-hospital cardiac arrest. Circulation

2015, 132, 1286-1300. doi:10.1161/CIR.0000000000000144.

Pulver, A.; Wei, R.; Mann, C. Locating AED enabled medical drones to enhance cardiac arrest response times. Prehosp Emerg Care 2016, 20(3), 378-389. doi:10.3109/10903127.2015.1115932.

Ringh, M.; Jonsson, M.; Nordberg, P.; Fredman, D.; Hasselqvist-Ax, I.; Håkansson, F.; Claesson, A.; Riva, G.; Hollenberg, J. Survival after public access defibrillation in Stockholm, Sweden - a striking success. Resuscitation 2015, 91, 1-7. doi:10.1016/j.resuscitation.2015.02.032.

Sanfridsson, J.; Sparrevik, J.; Hollenberg, J.; Nordberg, P.; Djärv, T.; Ringh, M.; Svensson, L.; 0622-6.

Williams, J.G.; Brice, J.H.; De Maio, V.J.; Jalbuena, T. A simulation trial of traditional 
Figure 1

Figure 1. Drone

Drone 


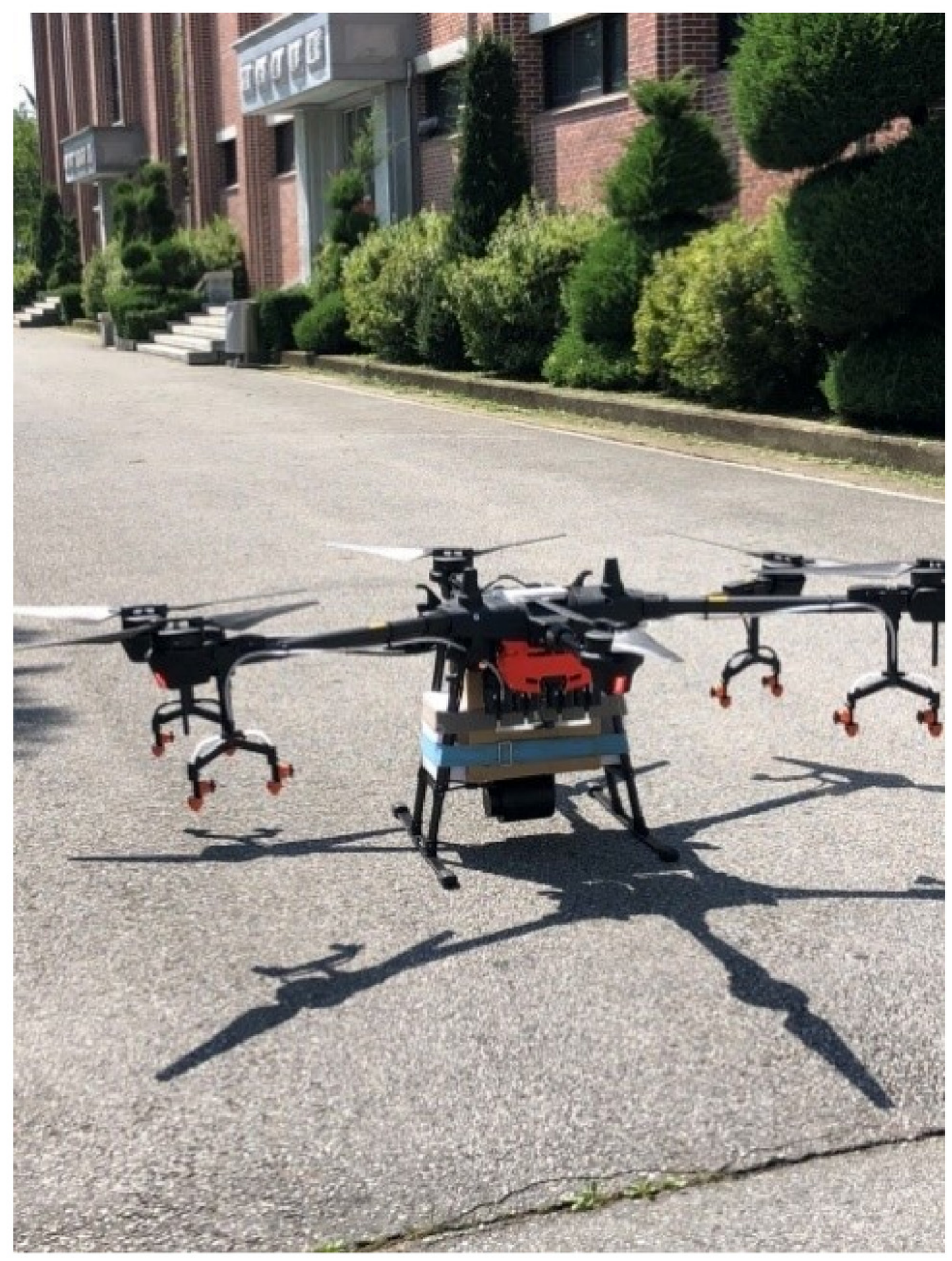


Figure 2

Figure 2. SimPad and Resusci Anne Q-CPR

SimPad $\square$ Resusci Anne Q-CPR 

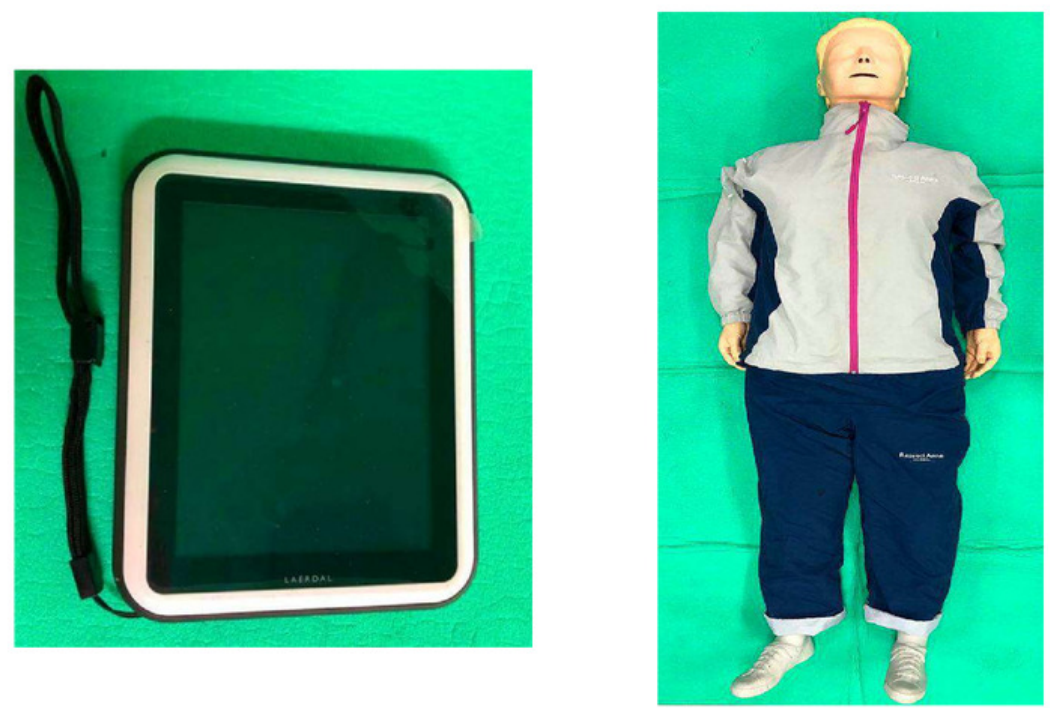


\section{Figure 3}

Figure 3. AED

Figure 3. AED

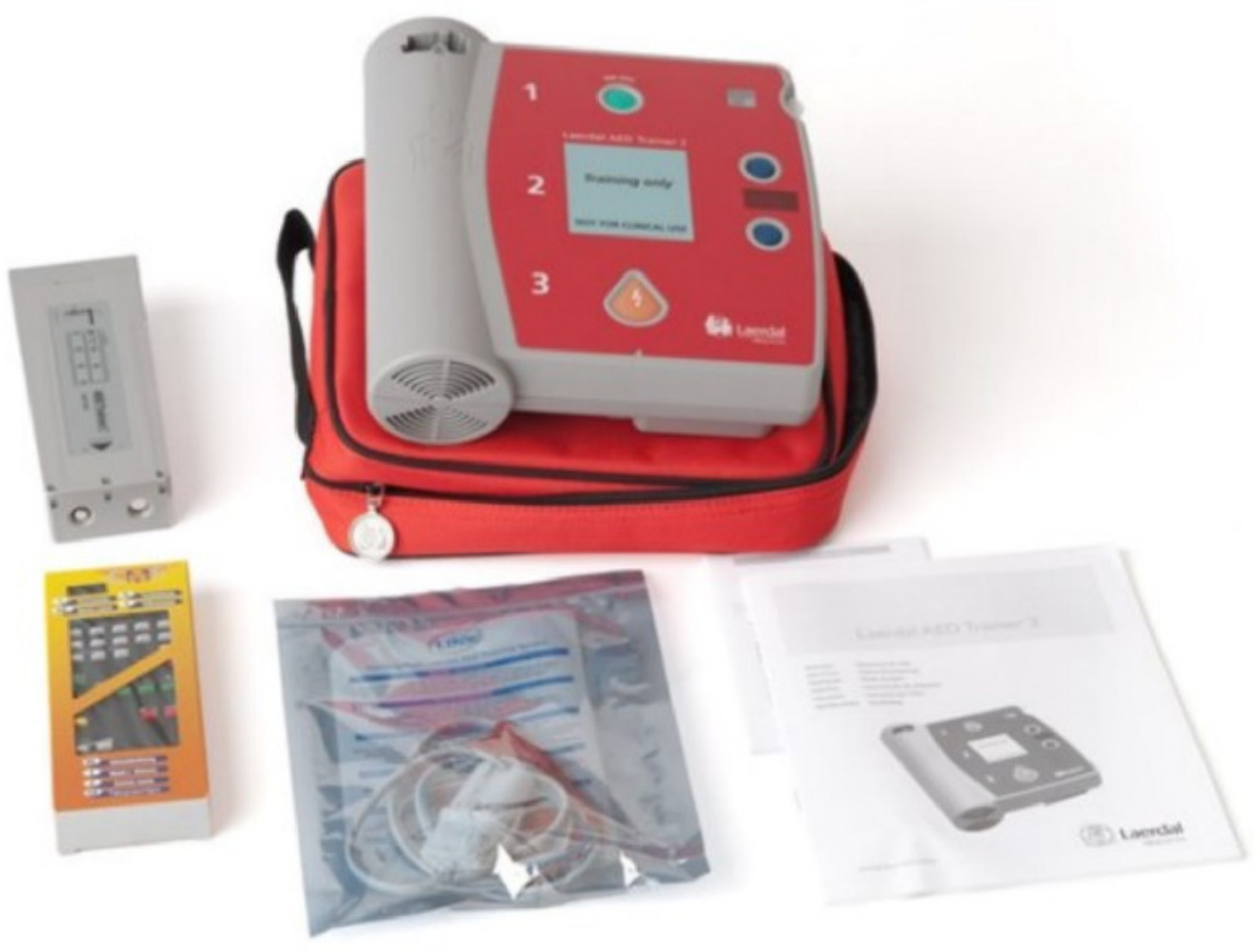


Figure 4

Figure 4. Flowchart of simulations

Figure 4. Flowchart of simulations 


\begin{tabular}{|l|l|l|}
\hline \multicolumn{1}{|c|}{} & \multicolumn{1}{c|}{ AED } \\
Cont. & transportation \\
& using drone \\
& & - CPR by 1 \\
& person with \\
& voice \\
& instruction \\
\hline
\end{tabular}

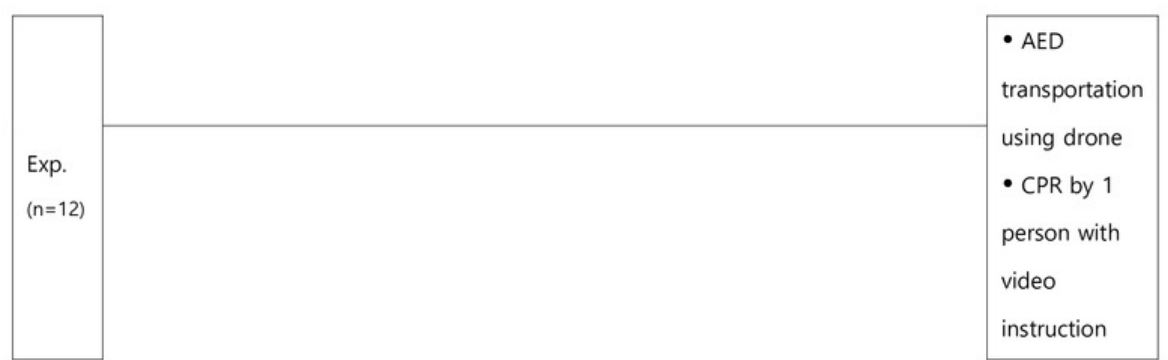


Table $\mathbf{1}$ (on next page)

General characteristics of participants

General characteristics of participants 
1 Table 1. General characteristics of participants $(\mathrm{N}=24)$.

\begin{tabular}{llll}
\hline & $\begin{array}{l}\text { Audio-instructed } \\
\text { CPR N(\%) }\end{array}$ & $\begin{array}{l}\text { Video-instructed } \\
\text { CPR N(\%) }\end{array}$ & $\mathbf{X}^{\mathbf{2}} / \mathbf{t}(\mathbf{p})$ \\
\hline Gender & & & \\
Men & $7(58.3)$ & $4(33.3)$ & $1.510(.219)$ \\
Women & $5(29.2)$ & $8(66.7)$ & $-.112(.811)$ \\
\hline Age & $22.33 \pm 1.67$ & $22.42 \pm 1.98$ & $2.299(.099)$ \\
\hline Height & $165.58 \pm 5.00$ & $164.50 \pm 7.69$ & $.739(.310)$ \\
\hline Weight & $64.75 \pm 11.06$ & $61.00 \pm 13.67$ & \\
\hline
\end{tabular}

2 
Table 2 (on next page)

Differences in CPR performance based on instruction method

Differences in CPR performance based on instruction method 
1 Table 2. Differences in CPR performance based on instruction method $(\mathrm{N}=24)$.

\begin{tabular}{|c|c|c|c|c|}
\hline & & $\begin{array}{l}\text { Audio } \\
\text { instruction }\end{array}$ & $\begin{array}{l}\text { Video } \\
\text { instruction }\end{array}$ & $\begin{array}{l}\text { P-value } \\
\text { 1) }\end{array}$ \\
\hline \multirow{8}{*}{$\begin{array}{l}\text { Chest } \\
\text { compressions }\end{array}$} & Score $(\%)$ & $76.67 \pm 32.55$ & $86.58 \pm 16.09$ & .621 \\
\hline & Frequency & $96.92 \pm 12.33$ & $121.42 \pm 17.23$ & .002 \\
\hline & $\begin{array}{l}\text { Average depth } \\
(\mathrm{mm})\end{array}$ & $52.17 \pm 12.10$ & $53.67 \pm 5.30$ & .487 \\
\hline & $\begin{array}{l}\text { Relaxation rate } \\
(\%)\end{array}$ & $71.67 \pm 34.55$ & $90.83 \pm 16.39$ & .063 \\
\hline & $\begin{array}{l}\text { Implementation } \\
\text { rate }(\%)\end{array}$ & $47.08 \pm 7.79$ & $62.67 \pm 12.75$ & .001 \\
\hline & $\begin{array}{l}\text { Hand position } \\
\text { accuracy (5) }\end{array}$ & $86.25 \pm 28.56$ & $98.42 \pm 5.49$ & .074 \\
\hline & $\begin{array}{l}\text { Compression } \\
\text { speed } \\
\text { (times/min) } \\
\end{array}$ & $108.58 \pm 3.60$ & $104.50 \pm 7.19$ & .099 \\
\hline & Hands-off time & $17.08 \pm 2.71$ & $10.83 \pm 2.92$ & .000 \\
\hline \multirow{5}{*}{$\begin{array}{l}\text { Artificial } \\
\text { respiration }\end{array}$} & Score $(\%)$ & $57.42 \pm 37.59$ & $73.58 \pm 33.04$ & .505 \\
\hline & $\begin{array}{l}\text { Total respiration } \\
\text { (times) }\end{array}$ & $3.50 \pm 2.20$ & $5.50 \pm 2.75$ & .048 \\
\hline & $\begin{array}{l}\text { Total average } \\
\text { amount (ml) }\end{array}$ & $370.75 \pm 193.67$ & $430.50 \pm 147.10$ & .435 \\
\hline & $\begin{array}{l}\text { Breathing at the } \\
\text { appropriate } \\
\text { volume }(\%)\end{array}$ & $57.75 \pm 45.63$ & $72.42 \pm 31.03$ & .929 \\
\hline & $\begin{array}{l}\text { Speed } \\
\text { (times/min) }\end{array}$ & $1.58 \pm 1.17$ & $5.58 \pm 1.44$ & .081 \\
\hline Total score & & $19.25 \pm 11.85$ & $63.17 \pm 24.10$ & .000 \\
\hline
\end{tabular}

2 1) Statistical significance was measured by the Mann-Whitney U-test. 
Table 3(on next page)

Difference in evaluation score based on instruction method

Difference in evaluation score based on instruction method 
1 Table 3. Difference in evaluation score based on instruction method $(\mathrm{N}=24)$.

\begin{tabular}{llll}
\hline & $\begin{array}{l}\text { Audio } \\
\text { instruction }\end{array}$ & $\begin{array}{l}\text { Video } \\
\text { instruction }\end{array}$ & $\begin{array}{l}\text { P-value } \\
\text { 1) }\end{array}$ \\
\hline Consciousness check & $1.50 \pm 0.52$ & $2.00 \pm 0.00$ & .006 \\
\hline 119 report \& defibrillator request & $0.92 \pm 0.28$ & $1.42 \pm 0.51$ & .010 \\
\hline Breathing check (4) & $3.58 \pm 0.51$ & $7.33 \pm 1.15$ & .868 \\
\hline Chest compressions (8) average & $7.69 \pm 0.45$ & $7.97 \pm 0.09$ & .050 \\
1 cycle & $7.69 \pm 0.45$ & $8.00 \pm .0 .00$ & .014 \\
2 cycle & $7.75 \pm 0.62$ & $8.00 \pm 0.00$ & .149 \\
3 cycle & $7.83 \pm 3.90$ & $7.91 \pm 0.289$ & .546 \\
Total score & $23.08 \pm 1.38$ & $23.92 \pm 0.29$ & .050
\end{tabular}

\begin{tabular}{llll}
\hline Airway check (4) & $4.00 \pm 0.00$ & $3.83 \pm 0.57$ & .317 \\
\hline Artificial respiration (8) average & $6.05 \pm 1.20$ & $6.58 \pm 1.27$ & .257 \\
1 cycle & $6.58 \pm 0.90$ & $6.50 \pm 0.80$ & .452 \\
2 cycle & $6.91 \pm 1.08$ & $7.00 \pm 1.21$ & .738 \\
3 cycle & $4.66 \pm 3.52$ & $6.25 \pm 2.26$ & .327 \\
Total score & $18.17 \pm 3.61$ & $19.75 \pm 3.82$ & .257 \\
& & & \\
\hline Defibrillator (10) & & & .707 \\
\hline Defibrillation time & $9.00 \pm .85$ & $9.00 \pm 1.04$ & .817 \\
\hline Total & $31.64 \pm 6.04$ & $32.23 \pm 7.90$ & .072 \\
\hline
\end{tabular}

2 
Table 4 (on next page)

Results of the qualitative content analysis

Results of the qualitative content analysis 
1 Table 4. Results of the qualitative content analysis $\left(\mathrm{N}_{-}=24\right)$.

\begin{tabular}{ll}
\hline Category & Subcategory \\
\hline Unfamiliar but beneficial & Regret for poor performance \\
\cline { 2 - 2 } experience & $\begin{array}{l}\text { Vibrancy, as if experiencing a real } \\
\text { situation }\end{array}$ \\
\hline Met helper during a desperate and & Comfort that you are not alone \\
\cline { 2 - 2 } embarrassing situation & Compensation for insufficiencies \\
\hline Different views on the use of & Conflicting feelings about the size of the \\
drones & drone \\
\cline { 2 - 2 } & Varying views on the accessibility of \\
& drones \\
\hline
\end{tabular}

2 